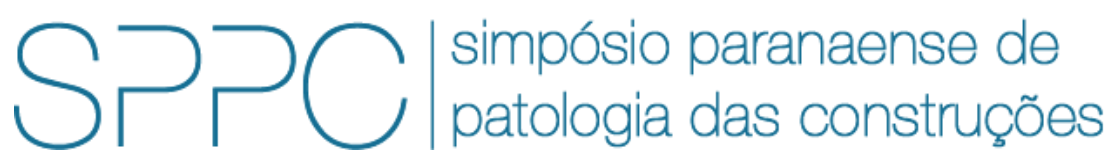

ISSN 2526-7248 artigo n. 2SPPC2006, pp. 523-536, 2017

\title{
Análise comparativa entre métodos de cálculo para estacas solicitadas por esforços horizontais
}

\author{
João Paulo Santos Silva ${ }^{1}$ e Eduardo Dell'Avanzi ${ }^{2}$ \\ ${ }^{1}$ Engenheiro Civil, Universidade Federal do Paraná, jpaulossilva93@gmail.com \\ 2 Engenheiro Civil/Ph.D, EGEL Engenharia Ltda./Universidade Federal do Paraná, \\ eduardo.dell.avanzi@gmail.com
}

Resumo: No caso geral, fundações em estacas devem ser projetadas para suportarem um sistema de cargas verticais, horizontais e momento. No caso do dimensionamento para suporte de cargas horizontais, deve-se atentar para três aspectos principais: capacidade resistente do solo para que não haja ruptura do mesmo, deslocamento máximo da estaca para que este não prejudique a estrutura e capacidade resistente da estaca para que ela não se rompa. A literatura apresenta diversos métodos para essas determinações, sendo cada um idealizado ou para verificação de apenas um desses aspectos ou para todos. O presente trabalho tem por objetivo a realização de um estudo comparando os resultados obtidos por quatro métodos diferentes: Brinch-Hansen, Broms, Briaud e resolução através do FTOOL. Assim, é possível a visualização das validações e inconformidades implícitas em cada método. A partir daí, cabe ao engenheiro a decisão do método de avaliação a ser utilizado para o projeto a ser analisado.

Palavras-chave: fundações profundas, esforços horizontais em estaca, capacidade última de carga em estaca, estudo comparativo, reação horizontal do solo.

Abstract: In the general case, pile foundations must be designed to withstand a system of vertical loads, horizontal loads and bending moment. To design de pile to support horizontal loads, attention should be paid to three main aspects: soil capacity that should be greater than the pressure on it, maximum displacement of the pile that should be less than the displacement that damage the structure and the pile capacity to not break it. The literature contains many methods to these determinations, each one was designed to check one or all of these aspects. This paper aims at conducting a study comparing the results obtained by four different methods: Brinch-Hansen, Broms, Briaud and resolution through FTOOL. Thus, it is possible to visualize implicit validations and nonconformities in each method. From there, it is up to the engineer to decide which method is better to solve a determined engineering problem.

Keywords: pile foundation, vertically loaded pile, ultimate lateral resistance of piles, comparative study, horizontal subgrade reaction. 
SILVA, J.P.S.; DELL'AVANZI, E., ESTUDO COMPARATIVO ENTRE MÉTODOS DE CÁLCULO PARA ESTACAS SOB AÇÃO DE ESFORÇOS HORIZONTAIS. $2^{\circ}$ Simpósio Paranaense de Patologia das Construções (20 SPPC), artigo 2SPPC2006, pp. 523-536, 2017. DOI: $10.4322 / 2$ SPPC.2017.043

\section{Introdução}

Estacas estão frequentemente sujeitas a esforços laterais e a momentos fletores. Estes esforços são advindos, por exemplo, da ação das ondas do mar e do impacto de embarcações nas estruturas de cais e portos; da ação das ondas e vento em estruturas offshore; da ação do solo em estruturas de contenção de terra; da ação da água em eclusas; da transmissão de esforços da edificação para a fundação e também da ação de abalos sísmicos sob a estrutura. Para o dimensionamento de fundações em estaca, dois critérios são devem ser considerados: um fator de segurança adequado contra seu rompimento e uma deformação aceitável para os carregamentos a que está sujeita. É usual analisar esses dois critérios separadamente, e dimensionar a estaca para que satisfaça ambos independentemente [3].

A reação produzida no solo, isto é, a transferência desses esforços laterais para o terreno, é um dos aspectos fundamentais no estudo de estacas carregadas horizontalmente, sendo um problema complexo. Essa reação é dependente das propriedades do solo onde a estaca se encontra, do tipo de solicitação (estática, cíclica, etc.) e também das propriedades da estaca (dimensões e módulo de elasticidade). Com o aumento do esforço horizontal atuante na estaca, é gerado um consequente aumento também no deslocamento horizontal da estaca e na reação do solo até que se atinge a ruptura do solo, considerando que a estaca tenha rigidez suficiente para resistir às solicitações fletoras que nela aparecem. Com isso, decorre a primeira verificação a ser feita: a ruptura do solo. Para que a solicitação de trabalho tenha uma adequada segurança em relação à solicitação de ruptura, é necessário primeiramente determinar os deslocamentos horizontais $e$ as solicitações fletoras na estaca. Para essa determinação, existem duas considerações do solo possíveis de serem feitas: ou como uma extensão da hipótese de Winkler, onde o solo é tratado como uma sequência de molas horizontais independentes entre si; ou o solo tratado como um meio contínuo elástico, sendo caracterizado por um módulo de Young e um coeficiente de Poisson. Qualquer que seja a consideração adotada deve ser verificada a possibilidade de a reação produzida ser maior do que a resistência do terreno, num processo à parte. Caso o solo seja tratado como uma sequência de molas, porém com reação nãolinear ("curvas p-y"), então o comportamento do solo é modelado até a ruptura [6].

Dentre os métodos desenvolvidos para a determinação da reação do solo a esses esforços laterais, destacam-se três (3): método de Brinch-Hansen (1961), método de Broms (1964) e um método mais recente desenvolvido por Briaud (1985).

Os métodos propostos por Brinch-Hansen e Broms dão como resultados a reação do solo e a distribuição de momentos fletores atuantes na estaca, tornando assim possível o cálculo da carga horizontal última, ou seja, a maior carga horizontal que o solo resiste antes da sua ruptura [6]. O deslocamento pode então ser encontrado adotando-se a hipótese de Winkler.

Em contrapartida, o método proposto por Briaud [1-2] resulta na definição não só da reação do solo e distribuição dos momentos fletores, como também nos deslocamentos e esforços cortantes resultantes do esforço horizontal aplicado, diretamente pelo método, a partir de propriedades do solo e da estaca juntamente com as solicitações presentes na estaca. 
Outra alternativa para obtenção das reações ao longo da estaca, aplicando-se a hipótese de Winkler, é a utilização do software FTOOL [4]. Neste, o solo pode ser representado por molas e aplicado então o esforço na estaca.

O objetivo do presente trabalho é estudar as diferentes hipóteses implícitas em diferentes métodos de cálculo de reação do solo a esforços horizontais através de análises comparativas e correlações de teorias. A realização de uma análise comparativa entre diversos modelos de solução para uma estaca carregada lateralmente ajuda para esse sucesso. Assim, podem-se visualizar suas aplicações e limitações, com base nos resultados encontrados, para cada aspecto a ser analisado.

\section{Modelos de cálculo}

Para a realização de uma análise comparativa entre os diferentes métodos de cálculo para determinação da carga horizontal última resistente de uma estaca foram tomadas estacas modelos, sendo uma curta e uma longa, e a partir delas determinadas as distribuições de tensões de acordo com a profundidade da estaca para cada método e com a aplicação da mesma carga no mesmo ponto de aplicação.

Esta análise foi realizada para aplicação em solo arenoso e para solo argiloso. Os modelos de estacas e solos adotados para o estudo são apresentados a seguir.

\subsection{Modelo de estaca curta}

Para o estudo de caso da aplicação dos métodos em estacas curtas, foi tomada como modelo uma estaca de seis (6) metros de profundidade enterrada e com uma força horizontal aplicada a dois (2) metros acima da superfície do terreno, como exemplificado na Figura 1 apresentada a seguir:

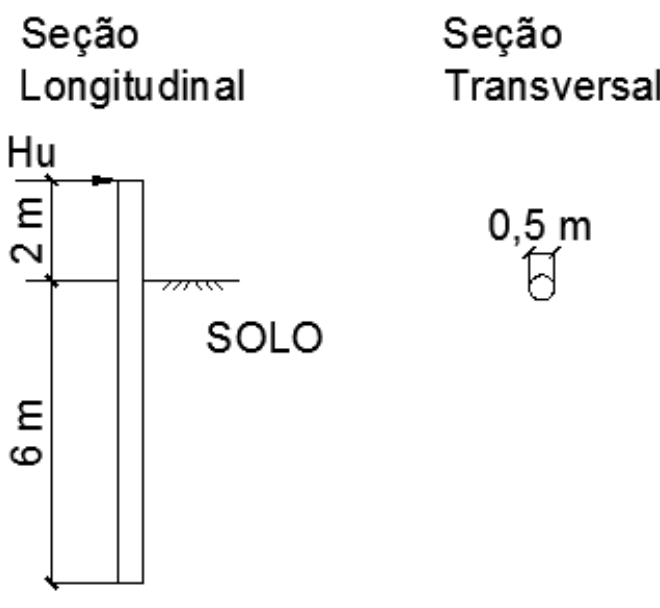

Figura 1: Modelo de estaca curta

A partir desse modelo, foram então determinadas as tensões ao longo do comprimento da estaca produzidas no solo pela aplicação dessa força horizontal. Essas distribuições de tensões foram determinadas a partir da discretização do solo em camadas de vinte e cinco (25) centímetros. 
O valor da força foi determinado de acordo com a menor carga horizontal última encontrada entre os métodos de Brinch-Hansen e Broms, aplicando-se então essa carga em todas as demais estacas para efeito comparativo.

\subsection{Modelo de estaca longa}

Para o estudo de caso da aplicação dos métodos em estacas longas, foi tomada como modelo uma estaca de vinte (20) metros, sendo dezoito (18) metros enterrados e outros dois (2) acima da superfície do terreno, com aplicação de uma força no topo superior dessa estaca como representado na Figura 2 a seguir:

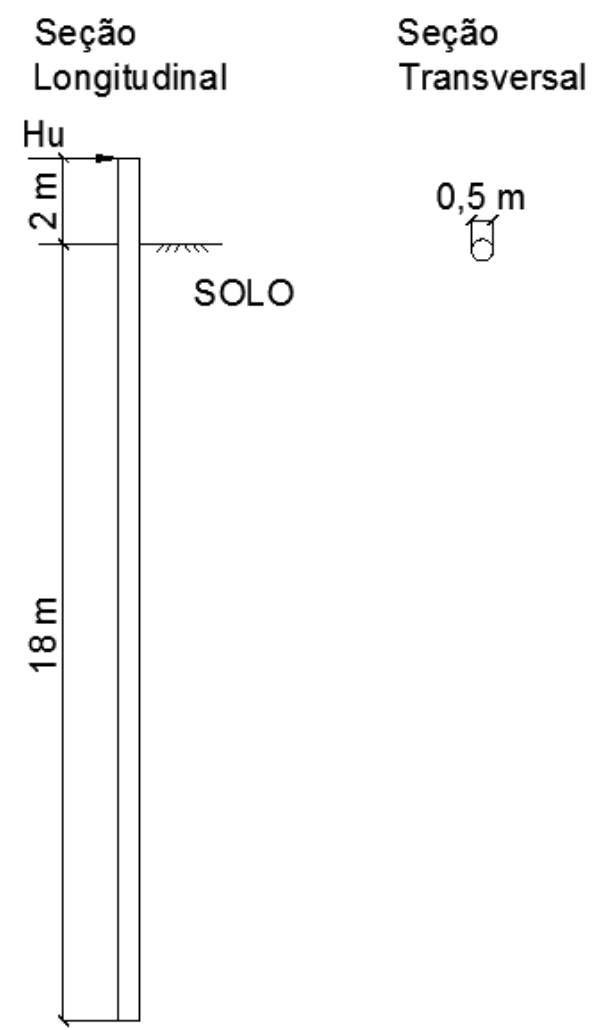

Figura 2: Modelo de estaca longa

A partir desse modelo, foram então determinadas as tensões ao longo do comprimento da estaca produzidas no solo pela aplicação dessa força horizontal. Essas distribuições de tensões foram determinadas a partir da discretização do solo em camadas de cinquenta (50) centímetros.

No caso de estacas longas submetidas a esforços horizontais, o ponto crítico do problema situa-se no rompimento da estaca, isto é, o dimensionamento deve ser feito para que a estaca aguente os momentos fletores solicitantes, tendo em conta que o rompimento da estaca ocorre antes do rompimento do solo.

Portanto, para o caso em questão, serão calculadas estacas submetidas aos mesmos esforços encontrados no caso das estacas curtas estacas curtas, levando em consideração que para a determinação da carga de ruptura é determinante o conhecimento do momento fletor resistente da estaca. 


\subsection{Modelo de solo arenoso}

Um dos solos tomado como exemplo para aplicação do modelo de cálculo foi uma areia compacta com as seguintes propriedades expressas na Tabela 1:

Tabela 1: Parâmetros da areia

\begin{tabular}{c|c}
\hline \multicolumn{2}{c}{ Parâmetros do Solo } \\
\hline $\mathrm{\gamma}\left(\mathrm{kN} / \mathrm{m}^{3}\right)$ & 20 \\
$\phi(\mathrm{Graus})$ & 35 \\
$\mathrm{c}(\mathrm{kPa})$ & 0 \\
$\mathrm{Ka}$ & 0,271 \\
$\mathrm{Kp}$ & 3,690 \\
\hline
\end{tabular}

Onde foram arbitrados os valores de massa específica do solo (Y), ângulo de atrito interno do solo $(\phi)$ e de coesão (c), e a partir desses valores calculados os valores dos coeficientes de empuxo ativo $(\mathrm{Ka})$ e passivo $(\mathrm{Kp})$ a partir da Teoria de Rankine. O coeficiente de reação horizontal do solo foi obtido através da teoria imposta por Therzaghi [5] considerando o solo como sendo areia compacta seca, com $n_{h}$ equivalente a $19,7 \mathrm{MN} / \mathrm{m}^{3}$.

\subsection{Modelo de solo argiloso}

O outro solo escolhido para a análise dos métodos foi uma argila dura fortemente pré-adensada com as seguintes propriedades apresentadas na Tabela 2:

\begin{tabular}{c|c} 
Tabela 2: Parâmetros da argil \\
\hline \multicolumn{2}{c}{ Parâmetros do Solo } \\
\hline y (kN/m³) & 25 \\
$\phi(\mathrm{Graus})$ & 25 \\
$\mathrm{C}(\mathrm{kPa})$ & 30 \\
$\mathrm{Ka}$ & 0,406 \\
$\mathrm{Kp}$ & 2,464 \\
$\mathrm{E}(\mathrm{kN} / \mathrm{m})$ & 138,81 \\
$\mathrm{Su}(\mathrm{MPa})$ & 75 \\
\hline
\end{tabular}

Assim como no caso da areia, a obtenção desses valores teve parte arbitrada e parte calculada. O coeficiente de reação horizontal também foi obtido através da teoria de Therzaghi [5]. Porém desta vez foi considerado como sendo constante ao longo de sua profundidade, com valor de $\overline{\mathrm{k}}_{\mathrm{s} 1}$ estipulado em 105,6 MN/m³.

\section{Resultados}

Realizados os cálculos para cada um dos quatro métodos estipulados para cada combinação estaca/solo possível, foi possível analisar e comparar os resultados. 


\subsection{Estaca curta em solo arenoso}

Aplicando-se os métodos de Brinch-Hansen e de Broms para a estaca curta em areia, a menor carga de ruptura encontrada foi de $311 \mathrm{kN}$, encontrada pelo método de Brinch-Hansen. Portanto, esta mesma carga foi utilizada para todos os demais métodos para efeito comparativo.

Cada método apresentou uma distribuição de tensões ao longo da profundidade diferenciada, como pode ser visto na Figura 3.a. Para todos os métodos, a somatória de tensões multiplicada pela altura de camada equivalente a 25 centímetros foi equivalente a $311 \mathrm{kN}$, que seria a força aplicada no topo da estaca. Portanto, para esse caso não houve inconformidades quanto a isso, tornando possível afirmar que todas as distribuições encontradas são plausíveis, mesmo talvez não sendo realista.
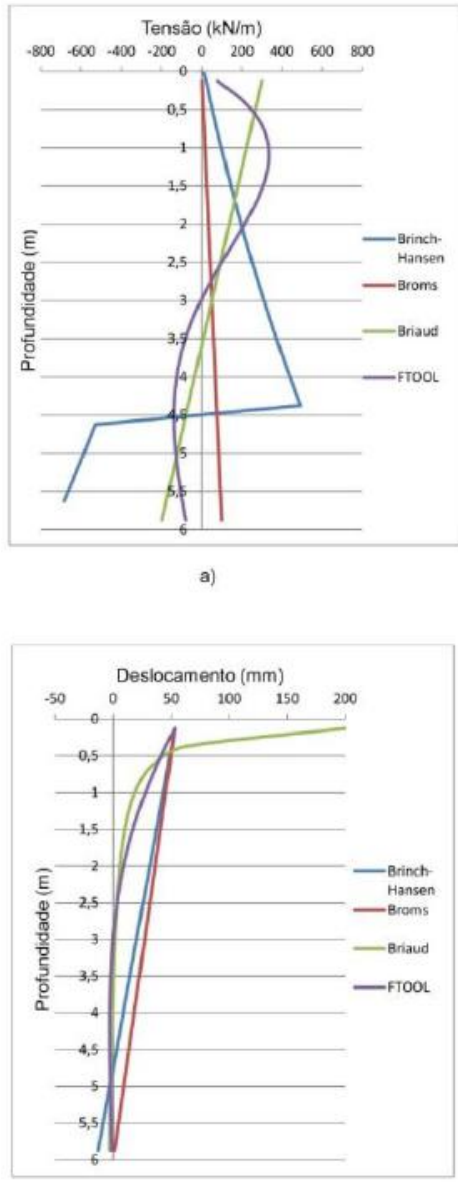

c)

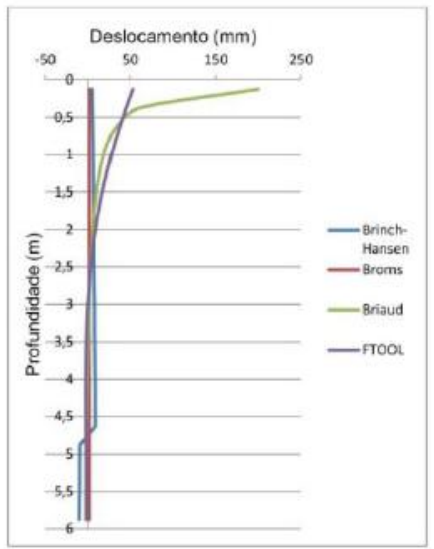

b)

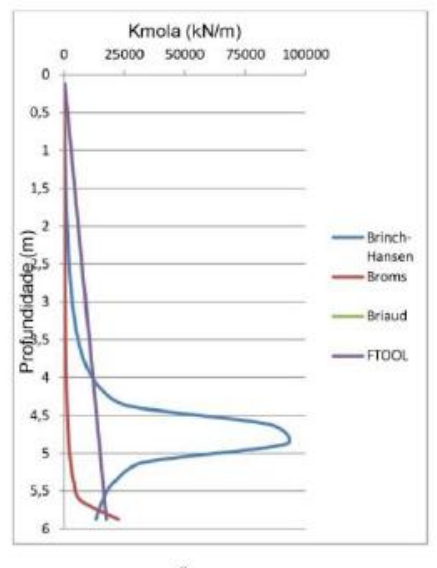

d)

Figura 3: Gráficos comparativos para estaca curta em areia: a) tensão encontrada ao longo da profundidade; b) deslocamentos ao longo da profundidade encontrados a partir da reação de cada método; c) deslocamento imposto ao longo da profundidade; d) coeficiente de reação horizontal do solo ao longo da profundidade encontrado a partir do deslocamento imposto. 
SILVA, J.P.S.; DELL'AVANZI, E., ESTUDO COMPARATIVO ENTRE MÉTODOS DE CÁLCULO PARA ESTACAS SOB AÇÃO DE ESFORÇOS HORIZONTAIS. $2^{\circ}$ Simpósio Paranaense de Patologia das Construções (20 SPPC), artigo 2SPPC2006, pp. 523-536,

Para obtenção dos deslocamentos da estaca, foram multiplicadas as tensões obtidas pela altura da camada de 25 centímetros, tendo assim uma força equivalente para cada camada. Após a obtenção dessas forças equivalentes, foram então multiplicados esses valores pelo coeficiente $\mathrm{K}_{\text {mola }}$ (coeficiente de reação do solo representado como mola, o mesmo utilizado na aplicação do método FTOOL para areia), tendo assim os deslocamentos causados pelas tensões impostas por cada método. Os deslocamentos encontrados são representados pela Figura 3.b.

Através da análise desses resultados, encontrou-se uma inconformidade de aplicação ao método de Brinch-Hansen, onde ocorre um brusco deslocamento exatamente no ponto de rotação da estaca encontrado pelo método. Interessante também observar o deslocamento constante obtido por Broms ao longo da profundidade, devido ao fato de tanto a distribuição de tensões quanto a distribuição de coeficiente de reação horizontal apresentar formatos triangulares. Sendo assim, esse deslocamento constante representa a razão entre essas distribuições.

Considerando que os deslocamentos encontrados pelos métodos de Brinch-Hansen e Broms através da aplicação do coeficiente de reação horizontal imposto por Therzaghi [5] não condizem com os deslocamentos estipulados por cada método, foram então calculados os coeficientes $\mathrm{K}_{\text {mola }}$ necessários para satisfazer a esses deslocamentos.

Em ambos os casos foram consideradas as estacas atuantes como rígidas, tendo deslocamento linear de acordo com a profundidade. Para o método de BrinchHansen, foi adotado deslocamento nulo no ponto de rotação da estaca obtido. No método de Broms, foi considerado como ponto de rotação o pé da estaca, tornando assim possível a distribuição de tensões impostas. Para ambos os métodos foram adotados deslocamentos a uma profundidade de 0,125 metros equivalente ao deslocamento encontrado através do método FTOOL. A Figura 3.c mostra os deslocamentos impostos no caso em questão, e a Figura 3.d representa os valores de $\mathrm{K}_{\text {mola }}$ necessários para atingir estes deslocamentos.

Nele, podemos observar que o coeficiente necessário para o método de Broms cresce de maneira exponencial de acordo com a profundidade, tendo em conta que o deslocamento imposto e a distribuição de tensões encontrada possuem valores inversamente proporcionais.

O coeficiente encontrado para o método de Brinch-Hansen também possui essa característica até seu ponto de rotação. Porém, a partir desse ponto, os deslocamentos tendem a aumentar assim como a distribuição de tensões, tornando assim necessário que o coeficiente de reação passa a diminuir exponencialmente. Realizando uma análise crítica, pode-se afirmar que o coeficiente de reação encontrado para o método de Brinch-Hansen não condiz com a realidade, tendo em vista o pico encontrado no ponto de rotação quando a tendência desse coeficiente é aumentar de acordo com a profundidade.

\subsection{Estaca curta em solo argiloso}

Para o caso da estaca curta em argila, a menor carga de ruptura encontrada entre os métodos foi de $418,125 \mathrm{kN}$, encontrada pelo método de Broms. Cada método também apresentou uma distribuição de tensões ao longo da profundidade 
diferenciada, porém sendo interessante observar a semelhança obtida entre os métodos de Brinch-Hansen e Broms. As distribuições de tensões por Brinch-Hansen e Broms respeitam as distribuições impostas pelo método, como pode ser visualizado através da Figura 4.a

Também para o caso da estaca curta em argila não houve inconformidades quanto a distribuição de tensões, tendo o produto da somatória de tensões pela altura da camada em todos os métodos equivalentes ou próximos a $418,125 \mathrm{kN}$, referentes à força horizontal aplicada.

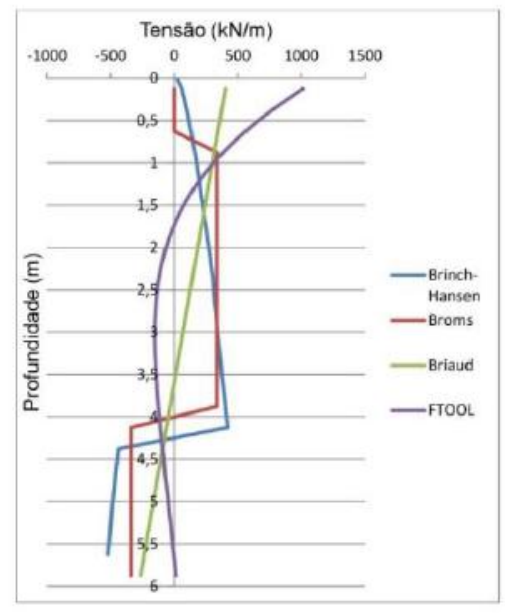

a)

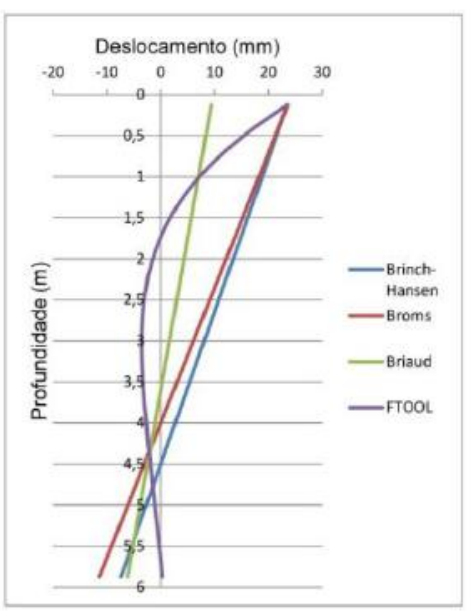

c)

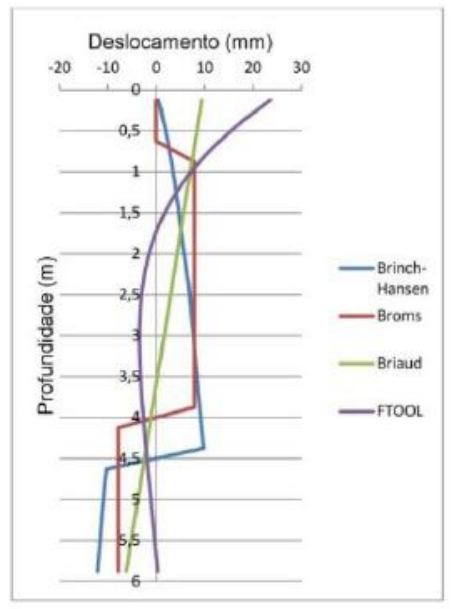

b)

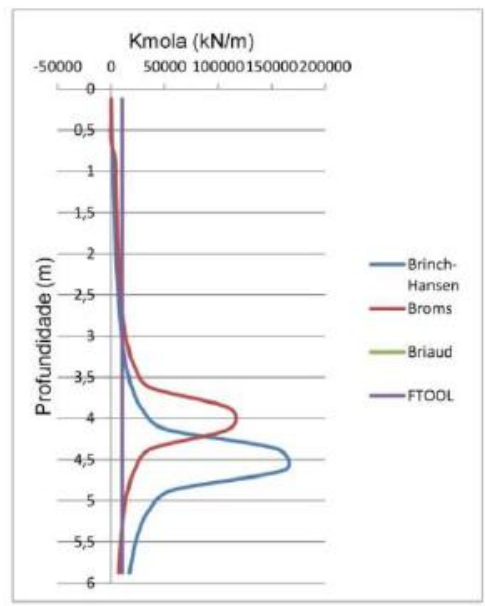

Figura 4: Gráficos comparativos para estaca curta em argila: a) tensão encontrada ao longo da profundidade; b) deslocamentos ao longo da profundidade encontrados a partir da reação de cada método; c) deslocamento imposto ao longo da profundidade; d) coeficiente de reação horizontal do solo ao longo da profundidade encontrado a partir do deslocamento imposto.

Para obtenção dos deslocamentos, foi utilizado o mesmo método que em areia, porém desta vez aplicando $0 \mathrm{~K}_{\text {mola }}$ referente ao solo argiloso (mesmo adotado na aplicação do método FTOOL para a argila). Devido ao fato do constante coeficiente de reação $\mathrm{K}_{\text {mola }}$ ao longo da profundidade, a configuração dos deslocamentos 
SILVA, J.P.S.; DELL'AVANZI, E., ESTUDO COMPARATIVO ENTRE MÉTODOS DE CÁLCULO PARA ESTACAS SOB AÇÃO DE ESFORÇOS HORIZONTAIS. $2^{\circ}$ Simpósio Paranaense de Patologia das Construções (20 SPPC), artigo 2SPPC2006, pp. 523-536,

encontrados é a mesma da distribuição de tensões, como pode ser verificado pela Figura 4.b.

Analisando os resultados obtidos através da Figura 4.b, observa-se que, para o caso da estaca em argila, os deslocamentos encontrados tanto para o método de Brinch-Hansen quanto para o de Broms não são condizentes com a realidade. Em ambos os casos há diferença de deslocamento brusca, sendo que pelo método de Broms isso ocorre duas vezes.

Assim sendo, realizou-se o mesmo procedimento realizado para areia, impondo-se deslocamentos para cálculo dos coeficientes de reações necessários para que tais deslocamentos ocorram. Os deslocamentos impostos podem ser observados através da Figura 4.c. Novamente, os deslocamentos a uma profundidade de 0,125 metros foram tomados estabelecidos como iguais ao obtido pelo método FTOOL. Os valores de coeficientes de reação obtidos podendo ser visualizados através da Figura 4.d.

Nele, podemos observar que o coeficiente necessário para o método de Broms parte de zero até uma profundidade equivalente a 1,5B (sendo $B$ a largura da estaca), assim como a distribuição de tensões. A partir dessa profundidade, 0 coeficiente começa a crescer exponencialmente, tendo em vista que 0 deslocamento diminui enquanto a tensão no solo permanece constante. Isso ocorre até uma profundidade de aproximadamente 4 metros, onde o coeficiente passa a decrescer da mesma forma devido à inversão da tensão nesse ponto.

O mesmo acontece para o método de Brinch-Hansen, porém essa inversão ocorre no ponto de rotação da estaca. O motivo é o mesmo do ocorrido em areia.

Realizando uma análise crítica, pode-se afirmar que os coeficientes de reações encontrados para os métodos de Brinch-Hansen e Broms não condizem com a realidade, tendo em vista o pico encontrado no ponto de rotação quando a tendência desse coeficiente é aumentar de acordo com a profundidade ou então permanecer constante, dependendo do tipo de solo.

\subsection{Estaca longa em solo arenoso}

No caso da estaca longa em areia, aplicando-se uma carga de $311 \mathrm{kN}$ na ponta da estaca, os métodos apresentaram esquemas de distribuição de tensões parecidos, com exceção de Brinch-Hansen. Para determinação da curva de distribuição de tensões pelo método de Broms os valores foram inseridos manualmente de modo qual a configuração dessa distribuição ficasse parecida com a estabelecida pelo método.

Realizando a somatória de tensões e multiplicando-a pela altura de discretização das camadas de 50 centímetros, observou-se que o valor obtido para o método de Briaud foi inferior aos $311 \mathrm{kN}$ de força aplicada. Isso implica em uma inconformidade, tendo em vista que a somatória de esforços seria diferente de zero.

Essa inconformidade se dá principalmente pelo fato do coeficiente de reação horizontal variável com a profundidade, que estabelece diferentes valores para o 
SILVA, J.P.S.; DELL'AVANZI, E., ESTUDO COMPARATIVO ENTRE MÉTODOS DE CÁLCULO PARA ESTACAS SOB AÇÃO DE ESFORÇOS HORIZONTAIS. $2^{\circ}$ Simpósio Paranaense de Patologia das Construções (20 SPPC), artigo 2SPPC2006, pp. 523-536, 2017. DOI: $10.4322 / 2$ SPPC. 2017.043

comprimento $\mathrm{I}_{0}$ (comprimento de transferência da estaca, explicado pelo método) ao longo da profundidade.

Os valores das distribuições de tensões são expressos pela Figura 5.a.

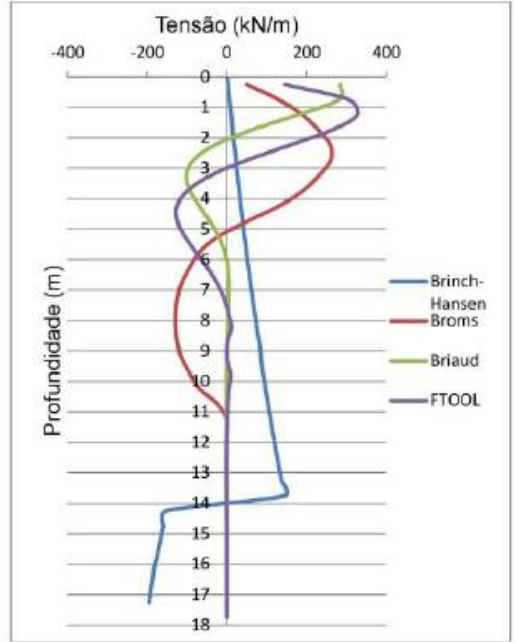

a)

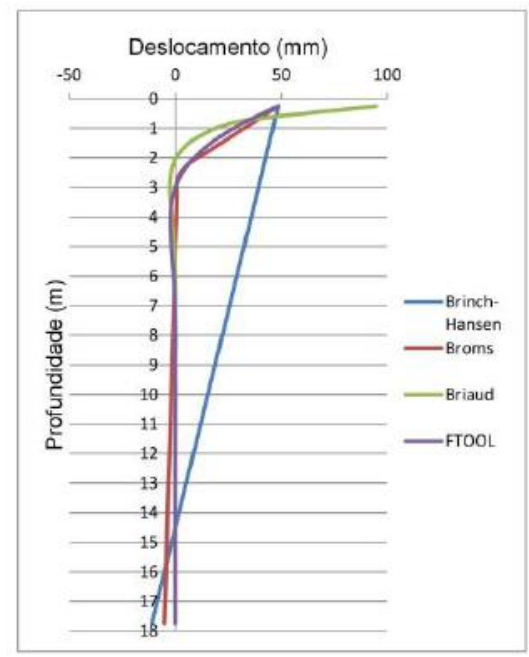

c)

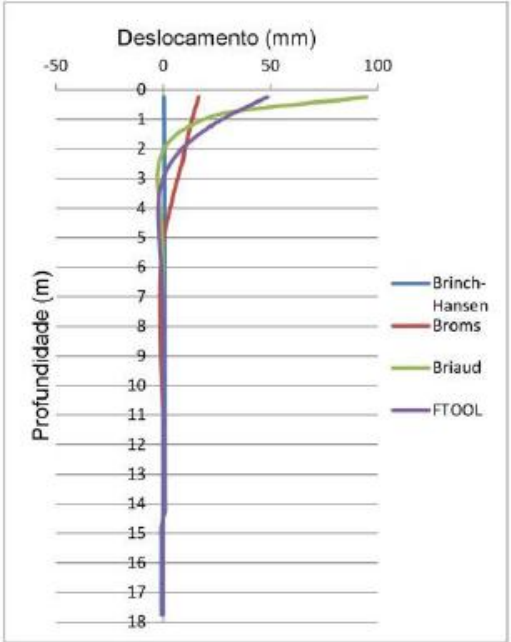

b)

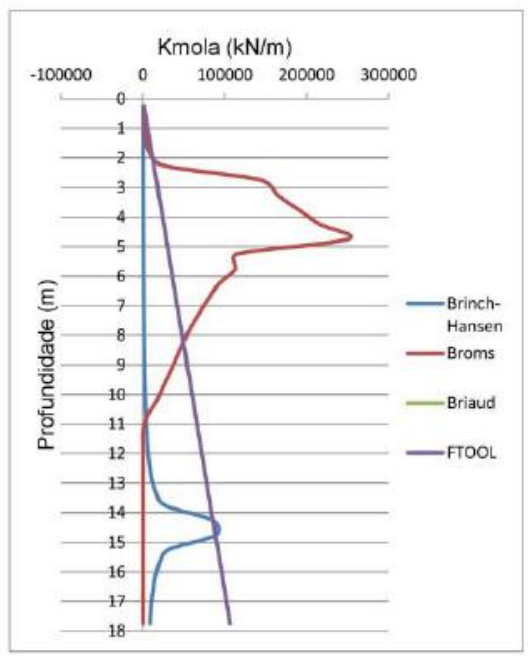

d)

Figura 5: Gráficos comparativos para estaca longa em areia: a) tensão encontrada ao longo da profundidade; b) deslocamentos ao longo da profundidade encontrados a partir da reação de cada método; c) deslocamento imposto ao longo da profundidade; d) coeficiente de reação horizontal do solo ao longo da profundidade encontrado a partir do deslocamento imposto.

O processo para obtenção dos deslocamentos da estaca é o mesmo idealizado para estacas curtas, sendo esse o produto das forças equivalentes de cada camada pelo coeficiente de reação $\mathrm{K}_{\text {mola }}$. Para este caso, apenas o método de Brinch-Hansen apresentou deslocamento não condizente com a realidade.

Porém, segundo o método de Broms, a estaca deveria apresentar a formação de uma rótula plástica a uma profundidade equivalente a $z_{0}$ (2,39 metros, para o caso) 
SILVA, J.P.S.; DELL'AVANZI, E., ESTUDO COMPARATIVO ENTRE MÉTODOS DE CÁLCULO PARA ESTACAS SOB AÇÃO DE ESFORÇOS HORIZONTAIS. $2^{\circ}$ Simpósio Paranaense de Patologia das Construções (20 SPPC), artigo 2SPPC2006, pp. 523-536,

enquanto apresentou a formação de rótula plástica somente a uma profundidade aproximada de 5 metros, como pode ser observado na Figura 5.b.

Para conformidade das hipóteses de Broms, foi imposta uma deformação tal que equivalha a uma formação de rótula plástica a uma profundidade de 2,39 metros, para assim determinação da distribuição de coeficientes de reações necessários para tal.

Os deslocamentos impostos, tanto para o método de Brinch-Hansen quanto para o de Broms são expressos através da Figura 5.c. O deslocamento a uma profundidade de 0,25 metro foi tomado de igual valor ao encontrado pelo método FTOOL. A Figura 5.d permite visualizar a distribuição do coeficiente de reação para tais deslocamentos.

Para o caso de Brinch-Hansen, o problema é o mesmo apresentado em estacas curtas, com a formação de um pico no ponto de rotação da estaca.

Para o caso de Broms, a esquematização apresentou formato totalmente disforme, sem nenhuma tendência. Isso ocorreu muito provavelmente devido ao fato de tanto a distribuições de tensões quanto as deformações impostas terem sido arbitradas. Mesmo obedecendo a hipóteses do método, não tem como se concluir exatamente o comportamento da estaca ao longo da profundidade pelo método de Broms.

\subsection{Estaca longa em solo argiloso}

Para o caso de estaca longa em argila, aplicando-se uma força de 418,125 kN na ponta da estaca, os métodos apresentaram esquemas de distribuição de tensões parecidos, com exceção de Brinch-Hansen. Para determinação da curva de distribuição de tensões pelo método de Broms os valores foram inseridos manualmente de modo qual a configuração dessa distribuição ficasse parecida com a estabelecida pelo método.

A integral das tensões ao longo da estaca teve valor igual ou próximo a 418,125 kN, referente à força aplicada ao todo, o que prova que não há maiores inconformidades com relação à distribuição de tensões.

Interessante atentar ao fato de que as resoluções obtidas pelo método de Briaud e pelo método FTOOL apresentaram praticamente o mesmo resultado, sendo inclusive difícil a separação das duas curvas de distribuição, como pode ser visualizado na Figura 6.a.

A determinação dos deslocamentos da estaca ao longo da profundidade foi realizada da mesma maneira que para os outros casos. Assim como no caso da estaca curta em argila, o deslocamento também apresentou esquema idêntico ao da distribuição de tensões, como pode ser observado através da Figura 6.b. Novamente, as deformações encontradas para 0 método de Brinch-Hansen apresentaram inconformidades. 


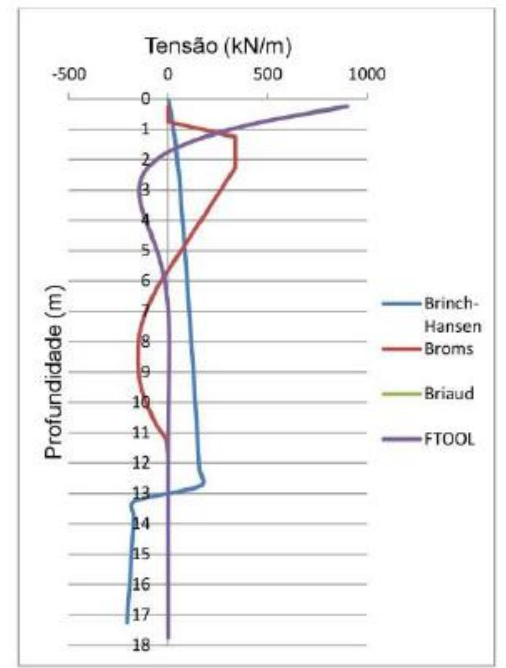

a)

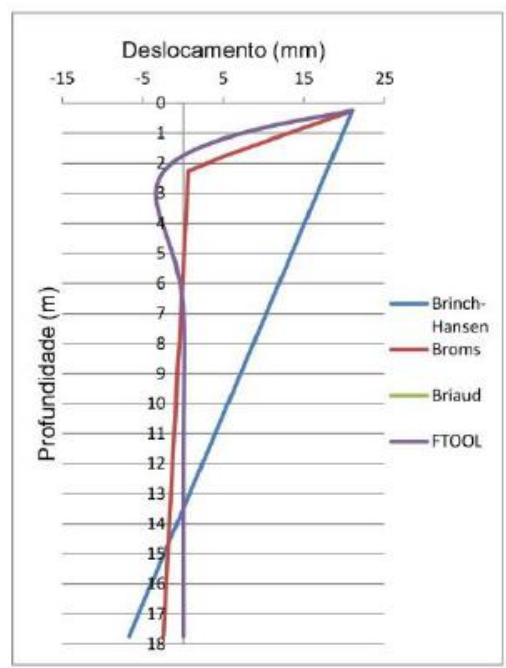

c)

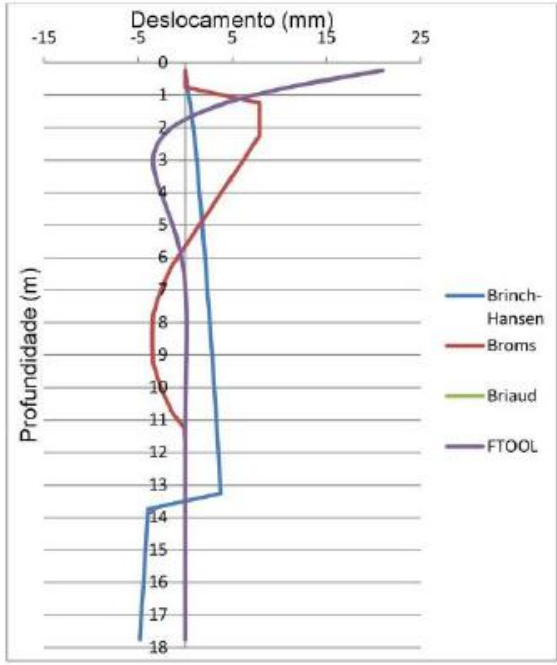

b)

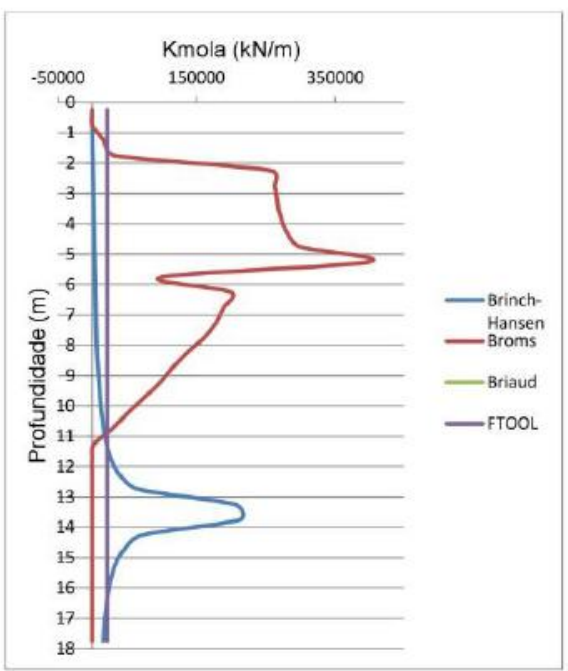

d)

Figura 6: Gráficos comparativos para estaca longa em argila: a) tensão encontrada ao longo da profundidade; b) deslocamentos ao longo da profundidade encontrados a partir da reação de cada método; c) deslocamento imposto ao longo da profundidade; d) coeficiente de reação horizontal do solo ao longo da profundidade encontrado a partir do deslocamento imposto.

O mesmo aconteceu para o método de Broms, porém devido ao fato de Broms considerar uma tensão nula até uma profundidade de 1,5B.

Para satisfação dos métodos de Brinch-Hansen e Broms, foram impostos deslocamentos da estaca ao longo da profundidade a fim de respeitar as condições de cada método. Novamente, o deslocamento a uma profundidade de 0,25 metros foi tomado de igual valor ao encontrado pelo método FTOOL. Os deslocamentos impostos são apresentados na Figura 6.c. 
SILVA, J.P.S.; DELL'AVANZI, E., ESTUDO COMPARATIVO ENTRE MÉTODOS DE CÁLCULO PARA ESTACAS SOB AÇÃO DE ESFORÇOS HORIZONTAIS. $2^{\circ}$ Simpósio Paranaense de Patologia das Construções (20 SPPC), artigo 2SPPC2006, pp. 523-536,

Para o caso de estaca longa em argila, ocorreu a mesma deformidade pelo método de Broms encontrada para o problema de estaca longa em areia. Novamente, a causa dessa deformidade é a não definição exata tanto da distribuição de tensões quanto do deslocamento da estaca.

Mais uma vez, a distribuição de coeficientes obtida para o método de Brinch-Hansen apresentou o mesmo problema, como pode ser visto na Figura 6.d.

\section{Conclusões}

Considerando a aplicação dos métodos para determinação da distribuição de tensões e também dos deslocamentos da estaca ao longo da profundidade em diferentes solos e com estacas de diferentes dimensões, o único método a não apresentar nenhuma inconformidade em nenhum dos casos apresentados foi 0 método realizado através do FTOOL. Através dele, a estaca pode ser verificada em relação a ruptura do solo, aos deslocamentos e também a ruptura da estaca, tendo em vista que o método também permite a visualização do diagrama de momentos fletores na estaca.

Outro método onde é possível a realização dessas três verificações foi o método desenvolvido por Briaud [1-2], onde também permite a determinação do diagrama de momentos fletores. Porém, a partir do estudo realizado, deve-se tomar cuidado com a determinação do coeficiente de reação horizontal do solo, tendo em vista que a distribuição de tensões ao longo da estaca apresentou inconformidades. Aquém dessa situação, aos demais casos o método se mostrou coerente.

Já os métodos de Brinch-Hansen e Broms demonstraram diversas inconformidades quando comparados a outras teorias, como a da distribuição de coeficiente de reação horizontal proposta por Therzaghi [5], não sendo então recomendados esses métodos para a determinação da distribuição de tensões e também de deslocamentos da estaca. Sendo assim, recomendam-se esses métodos apenas para a determinação da carga horizontal última de ruptura, como realizado no presente trabalho.

Deve-se também ressaltar que os altos valores encontrados foram devido ao fato da análise se basear em cargas de ruptura em uma estaca de seis metros, partindo da teoria de que o solo romperia antes da estaca. Porém, as dimensões desses valores não invalidam a análise.

\section{Referências}

[1] Briaud, J-L. (2013) Geotechnical Engineering - saturated and unsaturated soils. New York: John Wiley \& Sons.

[2] Briaud, J-L. (1997) SALLOP: Simple Approach for Lateral Loads on Piles. J. Geotech. Geoenviron. Eng., 123(10), 958-964.

[3] Poulos, H.G.; Davis, E.H. (1980) Pile Foundation Analysis and Design. New York: John Wiley \& Sons. 
SILVA, J.P.S.; DELL'AVANZI, E., ESTUDO COMPARATIVO ENTRE MÉTODOS DE CÁLCULO PARA ESTACAS SOB AÇÃO DE ESFORÇOS HORIZONTAIS. $2^{\circ}$ Simpósio Paranaense de Patologia das Construções (20 SPPC), artigo 2SPPC2006, pp. 523-536, 2017. DOI: $10.4322 / 2$ SPPC.2017.043

[4] PUC-RIO. (2015) Ftool - Two-Dimensional Frame Analysis Tool, Versão Educacional 3.01. Martha, Luiz.

[5] Terzaghi, K. (1955) Evaluation of coefficient of subgrade reaction. Geotechnique vol.5., n.4.

[6] Velloso, D.A.; Lopes, F. R. (2002) Fundações Profundas. COPPE - UFRJ.

[7] Rojas, José W. J. (2007) Estacas sob esforços transversais. Universidade Federal do Pampa. 